\title{
Simulasi Prakiraan Dan Klasifikasi Hujan Wilayah Kota jakarta dengan Metode Decision Tree
}

\author{
Arif Ega Prakosa ${ }^{1}$, Ahmad Fawaid ${ }^{2}$, Irkhas Nusantara ${ }^{3}$, Faisal Amri ${ }^{4}$, Aries Saifudin ${ }^{5}$ \\ Teknik Informatika, Universitas Pamulang, Tangerang Selatan, Indonesia

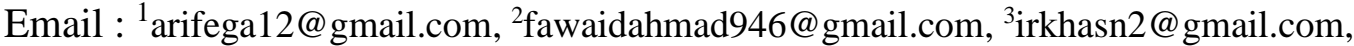 \\ ${ }^{4}$ faisalamryy@gmail.com, ${ }^{5}$ aries.saifudin@unpam.ac.id
}

Submitted Date: November $18^{\text {th }}, 2020$

Revised Date: November $25^{\text {th }}, 2020$

\author{
Reviewed Date: November $24^{\text {th }}, 2020$ \\ Accepted Date: April 01 ${ }^{\text {st }}, 2021$
}

\begin{abstract}
Rain is a natural occurrence that occurs in the hydrological and climatic circulation. Based on the ups and downs of the hydrological circulation, one of the sources of water is rain. rain is very useful in life, because rain can meet the needs of water for living creatures. However, rain can also cause floods. A flood tragedy can cause loss and casualties. Then our activities are checking the forecast simulation forecast and rain classification using the accurate decision tree method. We take forecast and classification data because the weather in DKI Jakarta is currently very difficult to predict. Next, we use a decision tree for data mining with a dataset spanning 5 years from 2011-2015. The problem here is the weather in DKI Jakarta which is very difficult to predict.
\end{abstract}

Keyword: Weather Data; Data Mining; Decision tree

\section{Abstrak}

Hujan adalah sebuah kejadian alam yang terdapat dalam sikulasi hidrologi dan iklim. Berdasarkan naik turun nya sirkulasi hidrologi salah satu sumber air adalah hujan. hujan sangat bermanfaat dalam kehidupan,karena hujan dapat memenuhi kebutuhan air untuk mahluk hidup.tetapi, hujan juga dapat menimbulkan bencana banjir. Tragedi banjir dapat menyebabkan kerugian dan korban jiwa. Kemudian kegiatan yang kami lakukan adalah meneliti untuk mengetahui simulasi prakiraan dan klasifikasi hujan dengan menggunakan metode Decision Tree seberapa tinggi intensitas akuratnya. Kami mengambil data prakiraan dan klasifikas karena cuaca di DKI Jakarta saat ini sangat susah untuk diprediksi. Selanjutnya kita menggunakan decision tree untuk data miningnya dengan dataset jangkauan 5 tahun dari 2011-2015. Masalah di sini yaitu cuaca di DKI Jakarta yang sangat sulit diprediksi.

Kata kunci: Data Cuaca; Data Mining; Decision tree

\section{Pendahuluan}

Air adalah sesuatu yang sangat penting bagi kehidupan makhluk hidup di dunia ini. Jadi air merupakan suatu hal yang sangat berharga. Air juga dapat dimanfaatkan untuk keperluan di berbagai bidang, misalnya untuk kebutuhan sehari-hari dan PLTA (Pembangkit Listrik Tenaga Air). Bisa disebut air merupakan anugrah dari tuhan yang membawa kesejahteraan bagi manusia dan semua makhluk hidup .

Dari dinamika siklus hidrologi salah satu sumber air utama adalah hujan. Dari alam hujan terjadi dari proses menguapnya air di udara yang selanjutnya membentuk gumpalan awan. Sifat hujan tergantung dengan kondisi cuaca yang terjadi pada saat itu. Ketersediaan air dari alam dalam jangkauan global yaitu tetap, hanya terjadi variasi baik pada ruang ataupun waktu pada saat skala regional. Sehingga dalam suatu pengamatan terhadap cuaca bisa diprediksi oleh cara simulasi (T. \& Sari, 2017). Untuk mengetahui simulasi perkiraan dan klasifikasi cuaca ini digunakan hasil data dari tahun ketahun pada setiap bulanya untuk menjadikan acuan cuaca pada bulan-bulan simulasinya.

Membuat materi simulasi prakiraan cuaca karena akhir - akhir ini cuaca susah ditebak tidak sesuai dengan bulannya sehingga diambil data untuk prakiraan ditarik dari 5 tahun sebelumnya bagaimana data hujan tapi hanya $50 \%$ akurat 
prakiraannya (Siregar, Faisal, Cahyana, \& Priyatna, 2020). Tingkat hujan dapat diukur dengan menggunakan alat pengukur hujan, alat yang digunakan untuk mengukur tingkat besar kecilnya hujan. Alat ini bekerja untuk mengumpulkan data curah hujan pada setiap tahun dan bulannya.

Kemudian Proses prakiraan cuaca memerlukan banyak data cuaca, jumlah data yang besar (Dhawangkhara \& Riksakomara, 2017). Data yang besar dapat mempercepat dan tepat dalam melakukan proses ini dengan menggunakan metode decision tree.

Dalam pengambilan data yang akan digunakan pada topic yang kami pakai dari data internet dari berbagai website resmi dari tahun ketahun untuk menentukan data yang akan digunakan (Lumbansiantar, 2019). Decision tree yang digunakan untuk mensimulasikan dan mengklasifikasikan cuaca akan memudahkan mendapatkan hasil yang dibutuhkan (Mendrofa, 2019).

Decision tree digunakan bermanfaat untuk membreakdown proses pengambilan keputusan yang susah dipahami agar mudah dipahami (Rosdiana \& Rismayana, 2018). Pengambilan keputusan akan lebih mengutamakan interpretasi solusi dari sebuah permasalahan.

Data mining untuk memprakiraan cuaca dengan menggunakan data cuaca beberapa tahun ke belakang (Maesaroh \& Kusrini, 2017). Bisa dibilang data mining berfungsi mendeskripsikan apa yang akan terjadi pada kedepannya. Salah satu contoh teknik descriptive data mining dan predictive data mining adalah klustering dan klasifikasi (Saifudin, 2018). Klustering digunakan pada saat data tidak diketahui bagaimana dikelompokkan atau pengelompokan data dengan cara membagi semua data menjadi kelompok-kelompok yang memiliki kesamaan (Gunadi \& Dewi, 2018). Setelahnya, suatu sistem akan mengklarifikasi data yang baru kedalam kelompok yang ada dan tidak ada tambahan kelompok data baru.

\section{Metodologi}

2.1 Metode

\section{Pengambilan data}

Pengambilan sumber tersebut dapat berupa buku bacaan, dan tesis yang berhubungan dengan topik yang diambil, maupun referensi langsung dari internet. Penelitian ini menggunakan pengambilan yang langsung dari internet.

\section{Pengolahan data awal}

Selanjutnya dalam pengolahan data berisikan pengecekan data yang mentah tadi yaitu melengkapkan data yang ada itu dengan menghapus data yang tidak digunakan supaya lebih mudah untuk mengelompokan datanya tersebut (Mujiasih, 2011).

\section{Analisis Kebutuhan dan Perancangan Sistem}

Selanjutnya pada tahap analisis kebutuhan sistem yang akan dibuat, kemudian membuat struktur desain sistem yang telah dianalisa.

\section{Implementasi dan Pengujian Sistem}

Sistem dibangun sesuai rancangan yang telah disetujui bersama, dalam hal ini sistem dibangun dengan menggunakan aplikasi berbentuk PHP dan Database. Selanjutnya menguji sistem yang terbentuk.

\section{Evaluasi dan validasi hasil}

Mengevaluasi dilakukan dengan mengamati hasil menggunakan algoritmanya. Validasi digunakan untuk memastikan bahwa hasil yang terakhir sudah sesuai dengan keinginan awal perancangan yang dibikinnya. Pengukuran kinerja dilakukan dengan membandingkan nilai ketepatan prediksi dan kesempurnaan data yang didapat (Laia \& Setyawan, 2020).

\section{Desain Rancangan}

Mengambil desain rancangan untuk memasukkan data setahun sebelumnya guna mengetahui prakiraan cuaca dan klasifikasi cuaca yang akan datang.

\subsection{Data}

\section{Dataset BMKG}

Ini data yang diambil dari dataset bmkg yang berisi tingkat jumlah curah hujan dan jumlah hari hujan di semua provinsi Indonesia dan yang digunakan hanya data provinsi DKI Jakarta dari tahun 2011 hingga 2015. 
Tabel 1 Data BMKG Indonesia

\begin{tabular}{|c|c|c|c|c|c|c|c|c|c|c|c|}
\hline \multicolumn{2}{|c|}{ Tahun } & \multicolumn{2}{|c|}{2011} & \multicolumn{2}{|c|}{2012} & \multicolumn{2}{|c|}{2013} & \multicolumn{2}{|c|}{2014} & \multicolumn{2}{|c|}{2015} \\
\hline Provinsi & Stasiun BMKG & $\begin{array}{c}\text { Jumlah Curah } \\
\text { Hujan }(\mathrm{mm})\end{array}$ & $\begin{array}{l}\text { Jumlah Hari } \\
\text { Hujan (hari) }\end{array}$ & $\begin{array}{c}\text { Jumlah Curah } \\
\text { Hujan (mm) }\end{array}$ & $\begin{array}{l}\text { Jumlah Hari } \\
\text { Hujan (hari) }\end{array}$ & $\begin{array}{c}\text { Jumlah Curah } \\
\text { Hujan (mm) }\end{array}$ & $\begin{array}{l}\text { Jumlah Hari } \\
\text { Hujan (hari) }\end{array}$ & $\begin{array}{c}\text { Jumlah Curah } \\
\text { Hujan (mm) }\end{array}$ & $\begin{array}{l}\text { Jumlah Hari } \\
\text { Hujan (hari) }\end{array}$ & $\begin{array}{c}\text { Jumlah Curah } \\
\text { Hujan (mm) }\end{array}$ & $\begin{array}{l}\text { Jumlah Hari } \\
\text { Hujan (hari) }\end{array}$ \\
\hline Aceh & Sultan Iskandar Muda & 1268.00 & 150.00 & 1098.00 & 137.00 & 1623.60 & 151.00 & 2264.40 & 142.00 & 1575.00 & 146.00 \\
\hline Sumatera Utara & Kualanamu' & 2042.00 & 225.00 & 3175.00 & 227.00 & 2627.00 & 218.00 & 2148.00 & 200.00 & 975.90 & 105.00 \\
\hline Sumatera Barat & Sicincin & & & 4339.00 & 230.00 & 4627.40 & 232.00 & 2838.40 & 163.00 & 3548.00 & 185.00 \\
\hline Riau & Sultan Syarif Kasim II & 2405.00 & 211.00 & 2636.00 & 217.00 & 2628.70 & 214.00 & 2343.70 & 188.00 & 2048.30 & 140.00 \\
\hline Jambi & Sultan Thaha ${ }^{2}$ & 2295.00 & 209.00 & 1874.00 & 191.00 & 2093.60 & 229.00 & 1781.00 & 199.00 & 1694.90 & 135.00 \\
\hline Sumatera Selatan & Kenten & 2593.00 & 217.00 & 3083.00 & 194.00 & 3409.20 & 238.00 & 1668.30 & 176.00 & 1947.20 & 138.00 \\
\hline Bengkulu & PulauBaai & & & 2545.00 & 143.00 & 3980.90 & 250.00 & 3323.00 & 174.00 & 2668.90 & 166.00 \\
\hline Lampung & Radin Inten II & 1568.00 & 118.00 & 1685.00 & 143.00 & 2456.70 & 198.00 & 1682.50 & 178.00 & 1628.10 & 151.00 \\
\hline Kepulauan Bangka Belitur & r Depati Amir & 2921.00 & 213.00 & 2018.00 & 195.00 & 2839.20 & 243.00 & 1675.00 & 179.00 & 1534.70 & 163.00 \\
\hline Kepulauan Riau & Kijang & 3893.00 & 205.00 & 3253.00 & 202.00 & 3389.40 & 227.00 & 3064.00 & 174.00 & 2250.90 & 174.00 \\
\hline DKI Jakarta & Kemayoran ${ }^{3}$ & 1274.00 & & 1570.00 & 139.00 & 2524.60 & 172.00 & 2908.00 & 157.00 & 2169.50 & 121.00 \\
\hline JawaBarat & Bandung & 1789.00 & 215.00 & 2510.00 & 219.00 & 2682.00 & 240.00 & 2388.00 & 226.00 & 2199.30 & 177.00 \\
\hline
\end{tabular}

\section{Dataset DKI Jakarta}

Ini dataset yang diambil langsung dari website cuaca DKI Jakarta dari tahun 2011-2014.

Tabel 2 Cuaca DKI 2011

\begin{tabular}{c|c|c|c}
\hline tahun & bulan & curah hujan $(\mathrm{mm})$ & banyak hari hujan \\
\hline 2011 & 1 & 145,6 & 25 \\
\hline 2011 & 2 & 230,7 & 18 \\
\hline 2011 & 3 & 147,7 & 18 \\
\hline 2011 & 4 & 106,8 & 16 \\
\hline 2011 & 5 & 198,9 & 12 \\
\hline 2011 & 6 & 70,5 & 10 \\
\hline 2011 & 7 & 18,1 & 7 \\
\hline 2011 & 8 & 1,5 & 2 \\
\hline 2011 & 9 & 52,6 & 2 \\
\hline 2011 & 10 & 80,1 & 12 \\
\hline 2011 & 11 & 44,6 & 14 \\
\hline 2011 & 12 & 177 & 17 \\
\hline
\end{tabular}

Tabel 3 Cuaca DKI 2012

\begin{tabular}{|c|c|c|c|}
\hline tahun & bulan & curah hujan $(\mathrm{mm})$ & banyak hari hujan \\
\hline 2012 & 1 & 275,1 & 24,5 \\
\hline 2012 & 2 & 157,9 & 16,8 \\
\hline 2012 & 3 & 173,6 & 17,5 \\
\hline 2012 & 4 & 196,2 & 14 \\
\hline 2012 & 5 & 118 & 11 \\
\hline 2012 & 6 & 67,2 & 4,5 \\
\hline 2012 & 7 & 13,6 & 1,5 \\
\hline 2012 & 8 & 2,4 & 1 \\
\hline 2012 & 9 & 16,2 & 3,8 \\
\hline 2012 & 10 & 44,3 & 5,3 \\
\hline 2012 & 11 & 251,9 & 19 \\
\hline
\end{tabular}

Tabel 2 Cuaca DKI 2013

\begin{tabular}{|c|c|c|c|}
\hline tahun & bulan & curah hujan $(\mathrm{mm})$ & banyak hari hujan \\
\hline 2013 & 1 & 621,9 & 23 \\
\hline 2013 & 2 & 146,6 & 20 \\
\hline 2013 & 3 & 184,4 & 16 \\
\hline 2013 & 4 & 204,3 & 18 \\
\hline 2013 & 5 & 101 & 12 \\
\hline 2013 & 6 & 256,7 & 19 \\
\hline 2013 & 7 & 256,7 & 19 \\
\hline 2013 & 8 & 61,4 & 8 \\
\hline 2013 & 9 & 49,5 & 5 \\
\hline 2013 & 10 & 110,1 & 9 \\
\hline 2013 & 11 & 196,6 & 14 \\
\hline 2013 & 12 & 338,9 & 23 \\
\hline
\end{tabular}

Tabel 2 Cuaca DKI 2014

\begin{tabular}{|c|c|c|c|}
\hline Tahun & Bulan & Curah Hujan $(\mathrm{mm})$ & Banyak Hari Hujan \\
\hline 2014 & 1 & 1075 & 26 \\
\hline 2014 & 2 & 689 & 22 \\
\hline 2014 & 3 & 174 & 20 \\
\hline 2014 & 4 & 168 & 16 \\
\hline 2014 & 5 & 47 & 10 \\
\hline 2014 & 6 & 174 & 12 \\
\hline 2014 & 7 & 214 & 16 \\
\hline 2014 & 8 & 39 & 4 \\
\hline 2014 & 9 & 0 & 1 \\
\hline 2014 & 10 & 52 & 4 \\
\hline 2014 & 11 & 65 & 11 \\
\hline 2014 & 12 & 211 & 15 \\
\hline
\end{tabular}

\section{Hasil dan Pembahasan}

\subsection{Hasil}

Dari data di atas kita bisa mendapatkan hasil untuk mensimulasikan dan mengklarifikasikan cuaca pada provinsi DKI JAKARTA untuk ke depannya. Menggunakan metode decision tree kita dapat melihat keefektivitasan dari data di atas sehingga kita bisa mengetahui apakah data tersebut bisa untuk mensimulasikan cuaca ke depanya. 
Data yang digunakan dalam bentuk exel dibuka menggunakan read xls seperti gambar di bawah untuk menvalidasikan.

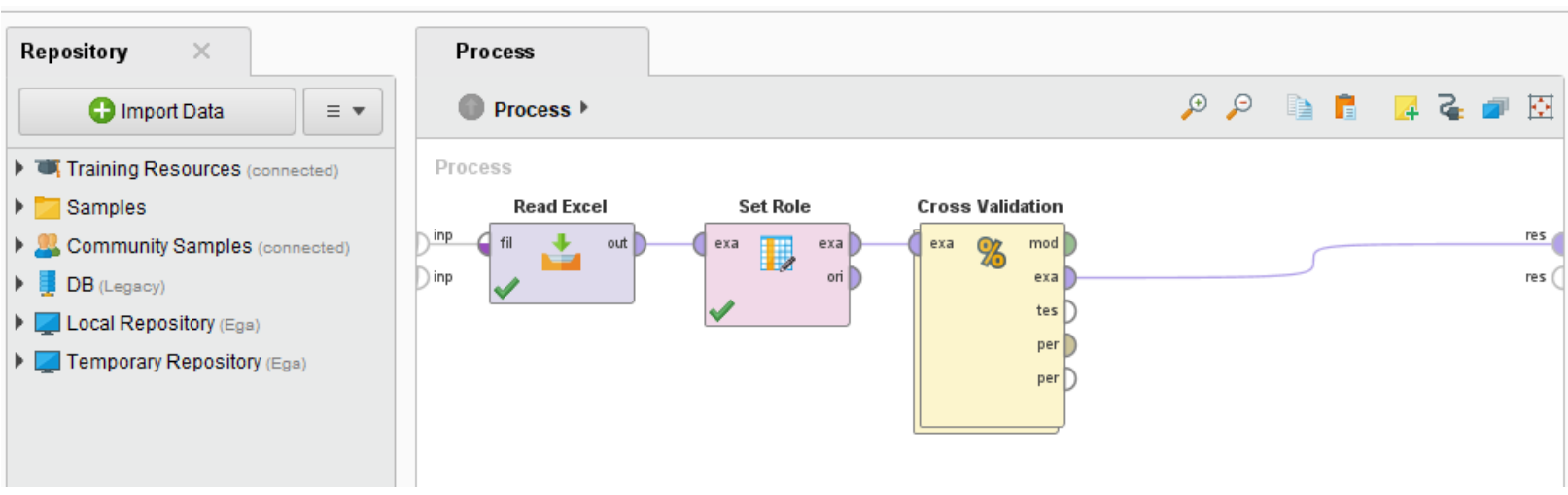

Selanjutnya setelah data dibuka melakukan menambahkan decision tree apply model dan tahap melatih dan menguji model dengan performance. Seperti gambar di bawah

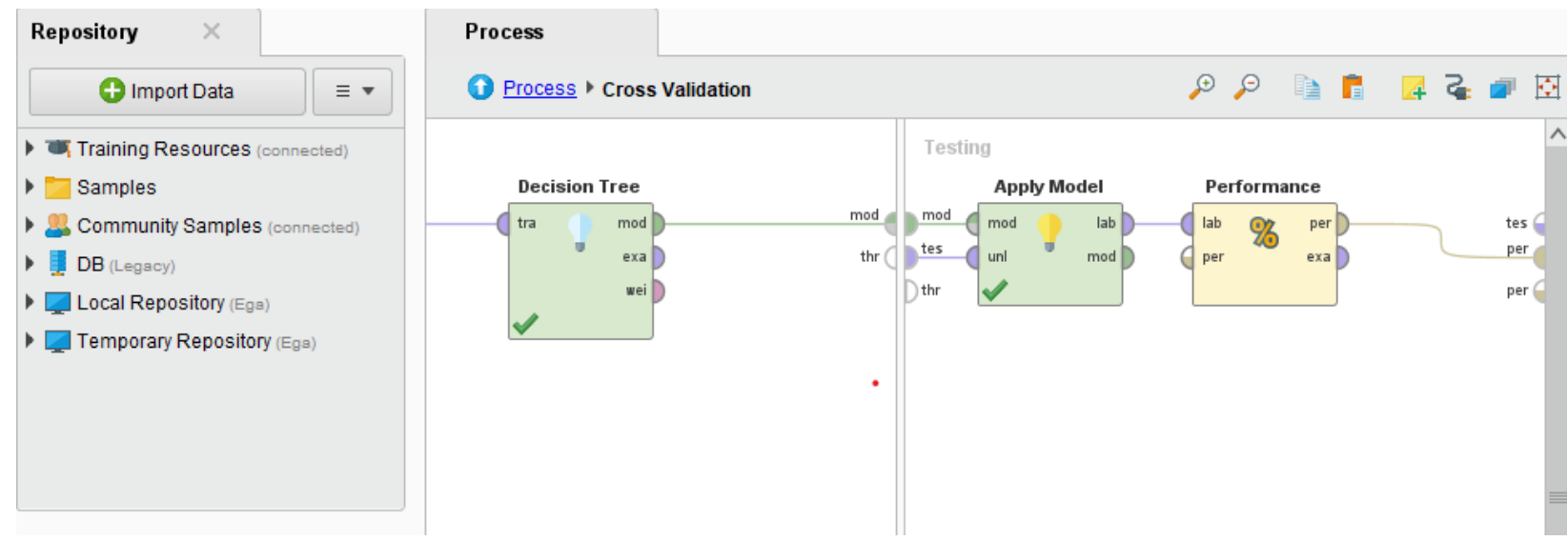

Selanjutnya kita mendapatkan hasilnya dari pengujian di atas yaitu 33,33\%

\begin{tabular}{|c|c|c|c|c|}
\hline & true Tahun & true Provinsi & true DKI Jakarta & class precision \\
\hline pred. Tahun & 1 & 1 & 1 & $33.33 \%$ \\
\hline pred. Provinsi & 0 & 0 & 0 & $0.00 \%$ \\
\hline pred. DKI Jakarta & 0 & 0 & 0 & $0.00 \%$ \\
\hline class recall & $100.00 \%$ & $0.00 \%$ & $0.00 \%$ & \\
\hline
\end{tabular}

\subsection{Pembahasan}

Pada data hasil di atas hanya mendapatkan $33,33 \%$ perisis nya dalam menggunakan metode decision tree. Sehingga masih ada cara yang lebih efektif untuk mensimulasikan dan mengklasifikasikan data yang sudah dapatkan. Jika kita gunakan untuk mensimulasikan mungkin kurang efektif menggunakan metode decision tree.
Dalam pembahasan disini suatu prakiraan dan pensimulasian dapat berjalan dengan metode decision tree. Tetapi keakuratannya masih belum begitu baik ketimbang metode lainnya yang ada.

\section{Kesimpulan}

Berdasarkan dari hasil di atas implementasi dan pengukuran modelnya dihasilkan data yang kurang presisi yaitu 33,33\% sehingga bisa saja untuk mensimulasikannya atau 
mungkin bisa menggukana metode atau pemahaman yang lain. Bisa saja mensimulasikannya tetapi tidak akurat untuk klasifikasi digunakan.

\section{Saran}

Dalam data di atas sangat bagus tetapi kurang cocok untuk metode yang digunakan karena hanya mendapatkan tingkat presisi yang kecil untuk mensimulasikan prediksi cuacanya sangat kecil tingkat kevalidanya prediksi cuacanya. Jadi harus menggunakan suatu metode yang cocok agar dapat mensimulasikan yang akurat.

\section{Referensi}

Dhawangkhara, M., \& Riksakomara, E. (2017). Prediksi Intensitas Hujan Kota Surabaya dengan Matlab menggunakan Teknik Random Forest dan CART (Studi Kasus Kota Surabaya). Jurnal Teknik ITS, 6(1), 94-99.

Gunadi, I. G., \& Dewi, A. A. (2018). Klasifikasi Curah Hujan di Provinsi Bali Berdasarkan Metode Naïve Bayesian. Wahana Matematika dan Sains: Jurnal Matematika, Sains, dan Pembelajarannya, 12(1), 14-25.

Laia, M. L., \& Setyawan, Y. (2020). Perbandingan Hasil Klasifikasi Curah Hujan Menggunakan Metode SVM dan NBC. Jurnal Statistika Industri dan Komputasi, 5(2), 51-61.

Lumbansiantar, D. S. (2019). Analisa Data Bencana Alam Untuk Prediksi Dampak Yang Ditimbulkan Dengan Algoritma J48 (Studi Kasus : Palang Merah Indonesia). KOMIK (Konferensi Nasional Teknologi Informasi dan Komputer), 3(1), 25-29. doi:10.30865/komik.v3i1.1562

Maesaroh, S., \& Kusrini, K. (2017). Sistem Prediksi Produktifitas Pertanian Padi Menggunakan Data Mining. Energy : Jurnal Ilmiah IlmuIlmu Teknik, 7(2), 25-39.

Mendrofa, Y. (2019). Implementasi Algortima C4.5 Untuk Memprediksi Tingkat Kerusakan Akibat Banjir (Studi Kasus : BPBD Prov.Sumut). Jurnal Pelita Informatika, 7(4), 584-592.

Mujiasih, S. (2011). Pemanfatan Data Mining Untuk Prakiraan Cuaca. Jurnal Meteorologi Dan Geofisika, 12(2), 189-195. doi:10.31172/jmg.v12i2.100

Rosdiana, D., \& Rismayana, A. H. (2018). Prediksi Waktu Tanam Cabai Menggunakan Algoritma C4.5. Prosiding SINTAK (pp. 436442). Semarang: Universitas Stikubank.

Saifudin, A. (2018). Metode Datamining untuk Seleksi Calon Mahasiswa Baru. Jurnal Teknologi, $\quad$ 10(1), 25-36. doi:10.24853/jurtek.10.1.25-36
Siregar, A. M., Faisal, S., Cahyana, Y., \& Priyatna, B. (2020). Perbandingan Algoritme Klasifikasi Untuk Prediksi Cuaca. Accounting Information System, 15-24.

T., P. B., \& Sari, R. D. (2017). Penerapan Data Mining untuk Prakiraan Cuaca di Kota Malang Menggunakan Algoritma Iterative Dichotomiser Tree (ID3). JOUTICLA, 3(2), 101-108. 